\title{
Donepezil improved cognitive and global function in mild to moderate Alzheimer's disease
}

\author{
Rogers SL, Farlow MR, Doody RS, et al. A 24-week, double-blind, placebo-controlled trial of donepezil in patients with Alzheimer's \\ disease. Neurology 1998 Jan;50:136-45.
}

\section{Question}

In patients with mild to moderate Alzheimer's disease (AD), can donepezil improve cognitive and global function?

\section{Design}

Randomised, double blind, placebo controlled trial with 24 weeks of treatment followed by a 6 week placebo washout phase.

\section{Setting}

20 sites in the US.

\section{Patients}

473 patients $\geqslant 50$ years of age (mean age 73 y, $62 \%$ women) with uncomplicated $\mathrm{AD}$ and no chronic medical illnesses.

\section{Intervention}

154 patients were allocated to $5 \mathrm{mg}$ /day of donepezil, 157 to 10 $\mathrm{mg}$ /day of donepezil $(5 \mathrm{mg}$ /day for the first week followed by 10 $\mathrm{mg}$ /day for the remainder of the study), and 162 to placebo. All treatments were followed by a 6 week placebo washout phase.

\section{Main outcome measures}

Scores on the cognitive portion of the Alzheimer's Disease Assessment Scale (ADAS-cog) and Clinician's Interview-Based Impression of Change scale that included caregiver supplied information (CIBIC-plus).

\section{Main results}

Cognitive function was improved in patients in the 5 and 10 $\mathrm{mg}$ /day donepezil groups compared with those in the placebo group based on the best score at weeks 12, 18, and 24 ( $\mathrm{p} \leqslant 0.001$ for all comparisons) (table). Clinicians' global ratings on the CIBIC-plus were also improved in the donepezil groups compared with placebo ( $p \leqslant 0.005$ at 24 weeks) (table). No differences existed between the treatment groups for cognitive function or global improvement at the end of the washout phase. No treatment benefit was seen for patient rated quality of life. Side effects of donepezil were generally transient and mild except for nausea and vomiting. $16 \%$ of patients in the 10 $\mathrm{mg} /$ day donepezil group discontinued treatment because of adverse effects compared with $6 \%$ in the $5 \mathrm{mg}$ /day group and $7 \%$ in the placebo group. $68 \%$ of patients assigned to the 10 $\mathrm{mg}$ /day donepezil group completed the study on their originally assigned treatment regimen compared with $85 \%$ in the $5 \mathrm{mg}$ /day donepezil group and $80 \%$ in the placebo group.

\section{Conclusion}

Donepezil improved cognitive and global function in patients with mild to moderate Alzheimer's disease.

Donepezil v placebo in mild to moderate Alzheimer's disease ${ }^{*}$

\begin{tabular}{|c|c|c|c|c|}
\hline Outcome & $\begin{array}{l}\text { Donepezil } \\
5 \mathrm{mg} / \text { day, } \\
10 \mathrm{mg} / \text { day }\end{array}$ & Placebo & $R B I(95 \% C I)$ & $N N T(C I)$ \\
\hline Improvement & $38 \%$ & $27 \%$ & $41 \%(0.4$ to 100$)$ & $10(5$ to 686$)$ \\
\hline $\begin{array}{l}\text { of } \geqslant 4 \text { points, } \\
\text { ADAS-cog }\end{array}$ & $54 \%$ & $27 \%$ & $100 \%(47$ to 176$)$ & $4(3$ to 7$)$ \\
\hline Improvement & $15 \%$ & $8 \%$ & $99 \%(2$ to 291$)$ & $14(7$ to 461$)$ \\
\hline $\begin{array}{l}\text { of } \geqslant 7 \text { points, } \\
\text { ADAS-cog }\end{array}$ & $25 \%$ & $8 \%$ & $225 \%(74$ to 515$)$ & $6(4$ to 12$)$ \\
\hline Improved on & $26 \%$ & $11 \%$ & $155 \%$ (51 to 335$)$ & $7(4$ to 14$)$ \\
\hline $\begin{array}{l}\text { CIBIC-plus } \\
(\leqslant 3)\end{array}$ & $25 \%$ & $11 \%$ & $136 \%(39$ to 305$)$ & $7(5$ to 18$)$ \\
\hline
\end{tabular}

*ADAS- $\operatorname{cog}=$ Cognitive portion of the Alzheimer's Disease Assessment Scale; CIBIC-plus = Clinician's Interview Based Assessment of Change-Plus. Other abbreviations defined in glossary. RBI, NNT, and CI calculated from data supplied by the authors.

Sources of funding: Eisai Inc, USA and Eisai Co Ltd,Japan.

For article reprint:Dr J Ieni, Eisai Inc, Glenpointe Centre West, 500 Frank W Burr Boulevard, Tea neck, NJ 07666-6741, USA. Fax +1 2016929183.

Abstract, commentary, and author's response also published in Evidence-Based Medicine.

\section{Commentary}

Imagine you have a car. If the car was working normally, you should be able to do 70 miles/hour. Instead you are only able to do 43 miles/hour. You spend 24 weeks and quite a bit of money and in the end you are able to do 46 miles/hour. Are you happy with the result?

This is the crucial question; although a 3 point difference between donepezil 10 $\mathrm{mg}$ /day and placebo on the 70 point ADAS-cog scale is statistically significant, is it clinically meaningful? The number needed to treat (NNT) gives a better indication of clinical utility. Comparing donepezil $10 \mathrm{mg} /$ day and placebo groups at end point, we have to treat 6 patients with donepezil $10 \mathrm{mg} /$ day rather than placebo, for 1 patient to improve by 7 points on the ADAS-cog. A NNT of 6 sounds unconvincing, but many psychiatric interventions are around this mark.
This is only the second published trial of donepezil, and both studies have been funded by the company that makes it. It appears to be methodologically sound, although the absence of caregiver quality of life measures and Activities of Daily Living outcomes is difficult to reconcile. Their previous 12 week study found no improvement in caregiver quality of life with donepezil. ${ }^{1}$

As with most phase 3 studies, the translatability of the results to routine practice is hampered by the health of the study population. The trial population is likely to be much more healthy than a population seen in routine clinical practice. Whether the results would be any different in a more heterogeneous population remains to be seen.

There is little doubt that donepezil does some good for some patients, and given its relatively good tolerability and safety profile, providing you can live with the cost, a therapeutic trial may be justified to find out whether the patient in front of you is one of the lucky ones.

\section{James P Warner, MB BS, MRCP(UK), MRCPsych Royal Free Hospital School of Medicine} London, UK

1 Rogers SL, Friedhoff LT, and the Donepezil Study Group. Dementia 1996;7:293-303.

\section{Author's response}

Maintaining function is a valued outcome in a progressive disease. Actually, for 6 patients given $10 \mathrm{mg}$ /day donepezil, 3 showed robust improvement ( $>4$ ADAS points), whereas 5 of 6 either improved or maintained cognitive function. Helping a failing car maintain or improve its current speed is better than allowing it to slow and ultimately stop. 